\title{
An Anthropometry Study of the Shoulder Region in a Chinese Population and its Correlation with Shoulder Disease
}

\author{
Estudio Antropométrico de la Región del Hombro en una \\ Población China y su Relación con Enfermedad del Hombro
}

\author{
Ming-Yang Yu*; Wei Zhang**; De-Bao Zhang*; Xiao-Dong Zhang** \& Gui-Shan Gu*
}

YU, M-Y.; ZHANG, W.; ZHANG, D-B.; ZHANG, X-D. \& GU, G.S. An anthropometry study of the shoulder region in a Chinese population and its correlation with shoulder disease. Int. J. Morphol., 31(2):485-490, 2013.

SUMMARY: Purpose: There is a paucity of data which reflected the relationship between morphology and incidence of shoulder disorders with respect to the ethnic Chinese population. We used anteroposterior radiographs to measure the Acromion Index (AI) and Acromioglenoid Angle (AA) of Chinese patients. The baseline was defined as the line that connected the superior and inferior osseous margins of the glenoid cavity. In order to calculate the AI, the distance from the baseline to the lateral margin of the acromion was measured and then divided by the distance from the baseline to the lateral aspect of the humeral head. The AA was defined as the angle formed by the intersecting line drawn tangent to the sclerotic line of the acromion undersurface and the baseline point. The AI and AA were determined in three groups: 165 patients (average age, 60.2 years) with chronic shoulder symptoms; in an age and gender-matched acute injury group of 61 patients (average age, 44.3 years); and in an age and gender-matched control group of 63 volunteers (average age, 37.3 years).The average AI and standard deviation was $0.72 \pm 0.06$ in shoulders with subacromial impingement syndrome, $0.59 \pm$ 0.06 in those with acute injury, and $0.66 \pm 0.06$ in normal shoulders. The average AA and standard deviation was $76.8^{\circ} \pm 7.02$ in shoulders with subacromial impingement syndrome, $84.2^{\circ} \pm 7.81$ in those with acute injury, and $80.0^{\circ} \pm 7.33$ in normal shoulders. The AI and AA varied between patients with acute and chronic shoulder problems.

KEY WORDS: Acromioglenoid angle; Acromion index; Chinese population; Rotator cuff Injuries; Acromial Tilt.

\section{INTRODUCTION}

Studies have shown the potential for correlating acromial forms with lesions of the rotator cuff (Farley et al., 1994; Neer, 1972; Panni et al., 1996; Yamamoto et al., 2010). In 1972 Neer introduced the concept of impingement at the shoulder, which he reported occurred between the under surface of the acromion and the humeral head. Since then, many studies have focused on coracoacromial arch characteristics, both radiographically and cadaveric specimens (Farley et al.; Panni et al.; Yamamoto et al.). Nyffeler et al. (2006) investigated the lateral extension of the acromion, which is known as the Acromion Index (AI) and its relationship to rotator cuff tears. In his study, the average AI (and standard deviation) was $0.73 \pm 0.06$ in patients with fullthickness rotator cuff tears, $0.60 \pm 0.08$ in patients with osteoarthritis, and $0.64 \pm 0.06$ in the normal shoulders. Banas et al. (1995), measured the angle between the undersurface of the acromion and the glenoid (Acromioglenoid Angle [AA]) using magnetic resonance imaging (MRI), and showed that as the angle decreased, the incidence of supraspinatus tendon disease significantly occurred. Shoulders with full-thickness rotator cuff tears had AAs less than $70^{\circ}$. In contrast, the control group, which consisted of 25 patients without any symptoms, had an average AA of $80^{\circ}$.

In this study, we evaluated the anthropometry of the coracoacromial arch in three different groups of a Chinese population. The study was completed to: (1) to identify relationship of AI and AA in a Chinese population; (2) explore whether the nature of coverage as provide by the coracoacromial arch complex to the gleno-humeral joint affect the stability of shoulder joint; (3) determine the acromion morphology in patients who suffered from acute injury, as well as in patients with chronic shoulder pain and subacromial impingement syndrome.

\footnotetext{
* The First Hospital of Jilin University, Changchun, China.

** China-Japan Union Hospital of Jilin University, Changchun, China.

Supported by Jilin provincial science and technology department, China.
} 


\section{MATERIAL AND METHOD}

Standardized true anteroposterior radiograph were performed to measure the AI (Fig. 1) (Nyffeler et al.). Patients were placed on the bucky with a neutral rotation of the forearm and the arm at the side of the body without any abduction. The scapular plane was angled 45 degrees to the coronal plane of the thorax. Thus, in order to obtain a true anteroposterior radiograph of the glenohumeral joint, the patient needed to rotate the body until the scapular plane was parallel to the X-ray cassette. The beam was angled 45 degrees to the scapular plane (Fig. 2). We ensured that the coronal plane of the thorax was parallel to the X-ray cassette. A standardized true anteroposterior radiograph of the glenohumeral joint was obtained in all the cases (Fig. 3).

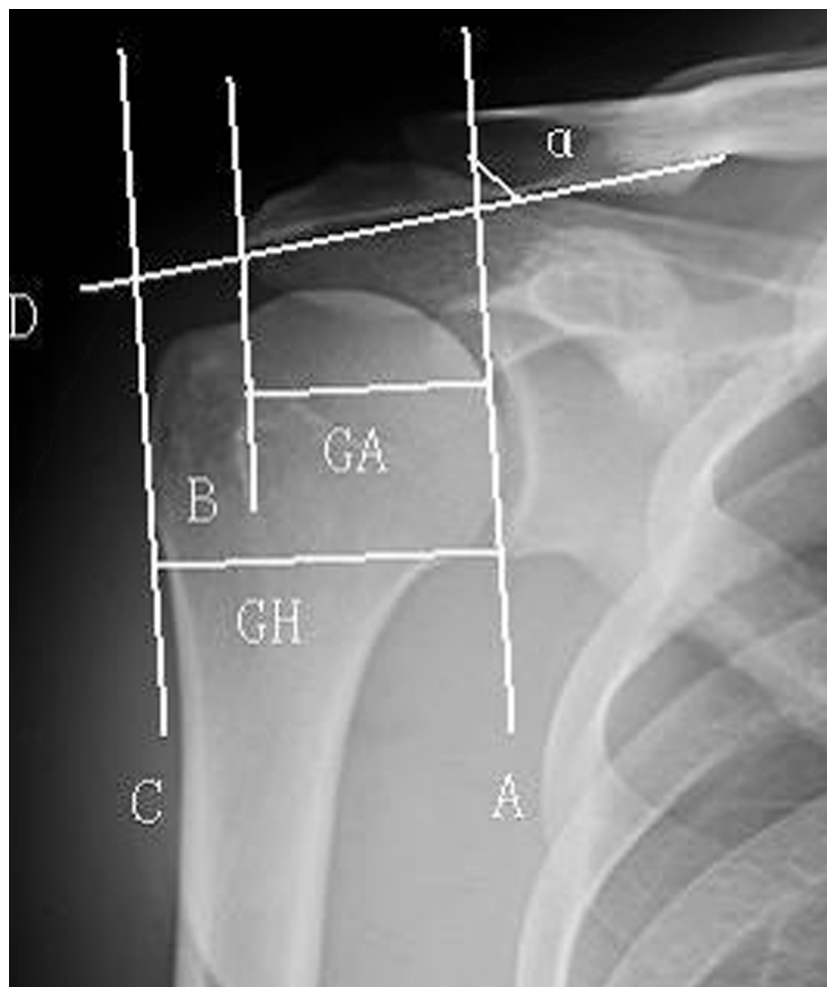

Fig. 1. Various parameters measured on standardized true anteroposterior radiograph for the purpose of this study. (A) Line A: tangential to the superior and inferior osseous margins of the glenoid cavity. Line B and C: parallel to line A and tangential to the margin of the acromion and the most lateral part of the proximal part of the humerus respectively. The acromion index (AI) was calculated by dividing the distance from line A to line B (GA) by the distance from the glenoid plane to the lateral aspect of the humeral head $(\mathrm{GH})$ calculated as distance between line A and C. (B) Line D is placed upon the sclerotic line, representing the "roof" at the undersurface of the acromion. a is the acromioglenoid angle (AA).

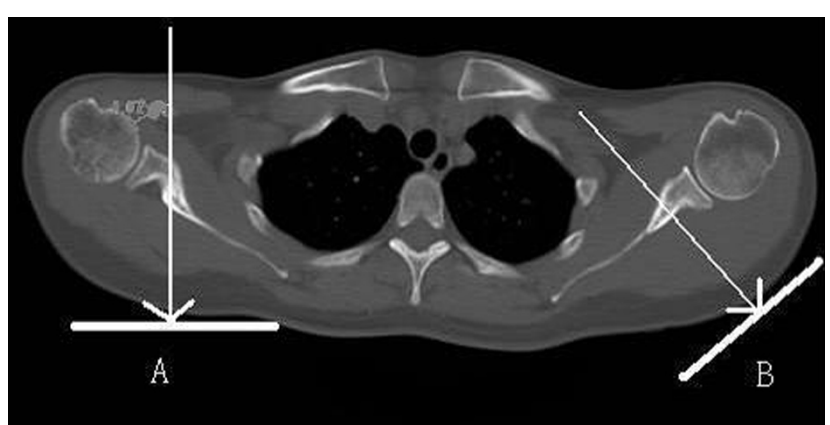

Fig. 2. An axial CT scan cut with an illustration demonstarting the correct technique of obtaining a standardized true anteroposterior radiograph of the shoulder. On the left hand side Image "A" shows the usual method of anteroposterior radiographs. "B" shows the correct method for standardized true anteroposterior radiograph, in which the beam is directed in the plane of the shoulder joint.

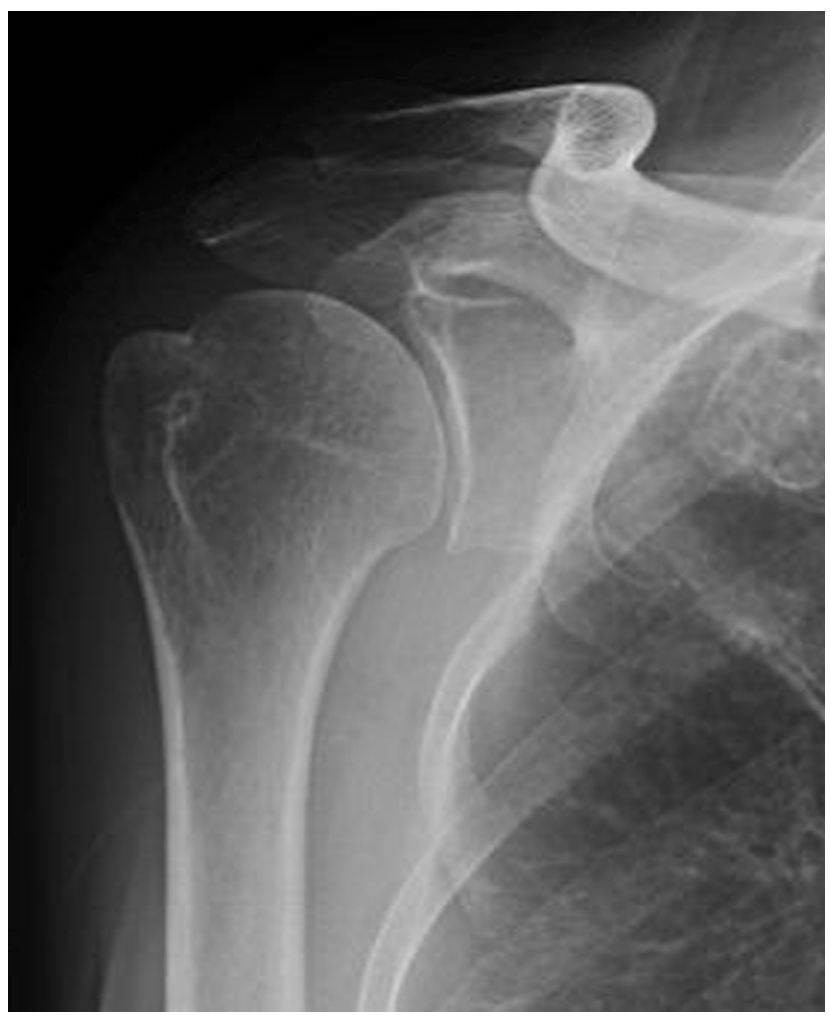

Fig. 3. A standardized true anteroposterior radiograph showing a. the middle part of clavicle is overlapping and b. the plane of glenoid is in a line.

Measurement of the AI. The AI is defined as the distance from the glenoid plane to the acromion (GA) divided by the distance from the glenoid plane to the lateral aspect of the humeral head (GH) (Niffeler et al.). As shown in Fig. 1, GA is the distance from line ' $\mathrm{A}$ ' to line ' $\mathrm{B}$ ', which crosses the superior and inferior cortical bone of the glenoid cavity lateral edge and the tangent line of the lateral acromion, respectively. $\mathrm{GH}$ is the distance from line ' $\mathrm{A}$ ' to line ' $\mathrm{C}$ ', which is the lateral tangent line of the proximal humerus. 
Measurement of AA. The same standardized anteroposterior radiographs used to measure the AI were used to calculate the AA (Fig. 1). The proximal line (line D) was placed tangent to the sclerotic line, representing the 'roof at the undersurface of the acromion. Some scholars also use this line to measure the acromiohumeral distance (Werner et al., 2008; Thompson et al., 2011). A second line was drawn tangentially to the superior and inferior osseous margins of the glenoid cavity, which is the same as in measuring AI. The AA (a) was formed by the intersection of line ' $D$ ' and line 'A' ( as described previously is drawn tangentially to superior and inferior osseous margins).

Patient and Control Groups. The patients were divided into three study groups: Asymptomatic or normal subjects; patients with chronic shoulder problems; and patients with acute shoulder injury.

The inclusion criteria for the group with acute injury were as follows: suffered a traumatic injury in the preceding two weeks and consequently had pain and limitations in shoulder motion. Patients with a history of trauma and inflammatory disease, as well as fracture, dislocation, chronic pain, or surgery on the shoulder of the affected side were excluded from this group. This series of consecutive patients included 37 men and 24 women who between 2008 and 2012. The average age of the patients at surgery was 43.3 years (range, 24-82 years).

The patients in the chronic group were selected from individuals suffering from chronic shoulder pain and had demonstrable impingement syndrome in the form of clinical painful arc syndrome. Patients with a history of heavy physical labor, trauma, inflammatory disease, fracture, surgery or a previous sportsman who often used the affected side were excluded. The chronic group of patients included 92 men and 73 women between 2008 and 2012. The average age of the patients at surgery was 59.8 years (range, 32-86 years).

The control group consisted of 63 volunteers who were asymptomatic and underwent a routine medical examination in our institution. We evaluated them using the Shoulder-rating Score Sheet, clinically evaluating them for any evidence of shoulder pathology emphasizing on the impingement sign, abduction and adduction sign, as well as evidence of any functional limitation and regional tenderness.. The control group included 36 men and 27 women. The average age of the volunteers is 37.4 years (range, 22-59 years).

Statistical analyses were performed using SPSS software package (version 13.0) We performed an analysis of the $t$ test, a value of $\mathrm{P}<0.05$ was set to show statistical significance.

\section{RESULTS}

The average AI (and standard deviation) was $0.72 \pm$ 0.06 in shoulders with subacromial impingement syndrome, $0.59 \pm 0.06$ in those with acute injury, and $0.66 \pm 0.06$ in normal shoulders. The average AA (and standard deviation) was $76.8^{\circ} \pm 7.02$ in shoulders with subacromial impingement syndrome, $84.2^{\circ} \pm 7.81$ in those with acute injury, and $80.0^{\circ} \pm$ 7.33 in normal shoulders. There was a statistical significance between the chronic and acute groups in both the parameters (both $\mathrm{p}<0.001$ ).

We also determined that both the AA and AI were independent predictors for subacromial impingement syndrome. In addition, AA and AI were inversely proportional to the symptoms in both groups (Figs. 4 and $5)$. This may be due to the fact that with an increase in the lateral extension of the acromion, the angle between the acromioglenoid decreases, which may increase the rate of impingement and provide an increased stability to the joint.

\section{DISCUSSION}

This study demonstrated a distinct correlation between the acromial morphology and incidence of shoulder pathology in a Chinese population. Previous anthropometric studies on western patients have also demonstrated similar findings (Epstein et al., 1993; Toivonen et al., 1995; Tetreault et al., 2004). Neer hypothesized that the critical area for degenerative tendinitis and tendon rupture was centered in the supraspinatus tendon. He also proposed that elevation of the arm during internal rotation or in the anatomical position of external rotation causes the critical area to pass under the anterior process of the acromion. Bigliani (1986) classified the shape of the acromion into three types and found that type III (hooked) acromion had a higher incidence of rotator cuff tears than type I (flat) or type II (curved) acromion. Aoki et al. (1986), used lateral radiographs to demonstrate the relationship between acromion with a flatter slope and rotator cuff diseases. Torrens et al. (2007), studied the influence of the acromial coverage index in rotator cuff tears, and found that patients with a cuff tear had a significantly higher acromial coverage index than the normal groups. A correlation between the acromiohumeral interval and the incidence of shoulder pathology has been demonstrated by many scholars (Thompson et al.; Werner et al.). An acromiohumeral interval less than $7 \mathrm{~mm}$ is indicative of superior humeral head migration and is potentially susceptible to the development of shoulder disease symptoms. 

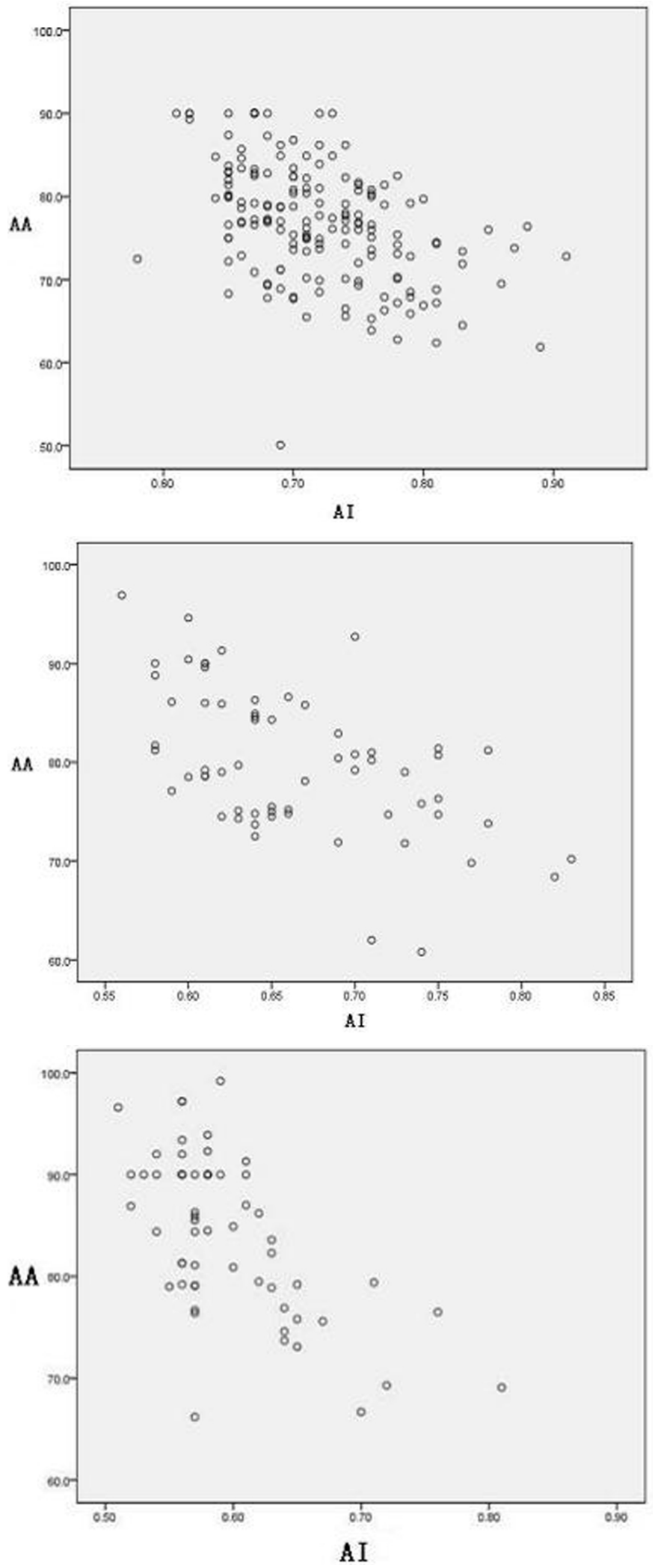

Fig. 4. The negative linear relationship between AI and AA in all groups. (A) The group with chronic pain; (B) The group of asymptomatic patients; (C) The acute injury group.
In our study, we believe that a wide range of diverse morphology seen in this study group could be secondary to congenital and osteal etiological factors, which is responsible for the gradual and steady damage to the soft tissues that move under the coraco acromial arch.

In contrast, this study demonstrated that there was no statistically significant association between a low AI and the development of osteoarthritis of the shoulder joint in a Chinese population. It is also interesting to note that in this Chinese patient population, despite the presence of radiographical changes of osteoarthritis in the shoulder joint, the morbidity of osteoarthritis in shoulder joint was very low. We also found that patients with a lower AI and larger AA were more prone to present symptomatically when they suffered direct trauma. A possible explanation to this finding is that AI and AA can affect the stability of the shoulder. Furthermore, the acromion morphology plays an important role in the stability of the shoulder joint, such that deeper concavities require a larger displacing force for a given compression load. Theoretically, the lateral extension and the angle of the acromion influence the coverage of the humeral head (Fig.6). The acromion thus makes some contribution to prevent the upward dislocation of the humeral head when the patient is subjected to a force from the inferior direction. In contrast, with the decrease of AI and increase of AA, a relatively small force transmitted during injury may cause increased damage. Therefore, trauma in these cases would be due to soft tissues resulting in symptoms.

This study brings forth some interesting conclusions: an increased AI and decreased AA led to increased shoulder joint stability, but the patient was prone to be subacromial impingement; inversly, shoulders with a decreased AI and increased AA had more flexibility, but were prone to dislocation and soft tissue injury, which could lead to greater incidence of symptomatic presentation.

This study has some limitations. Only two of the described congenital and osteal etiological factors were studied, and the acromial type or acromiohumeral interval were not assessed in this study. This may impact or skew our findings, especially in the groups with chronic symptoms, which may be due to various morphometric variations in and around the coracoacromial region. However, despite these limitations, the study demonstrated that AI and AA play a crucial role in the development of rotator cuff injuries. Another possible limitation of the study is that there may be a bias in classifying patients into subgroups, as some of the patients 


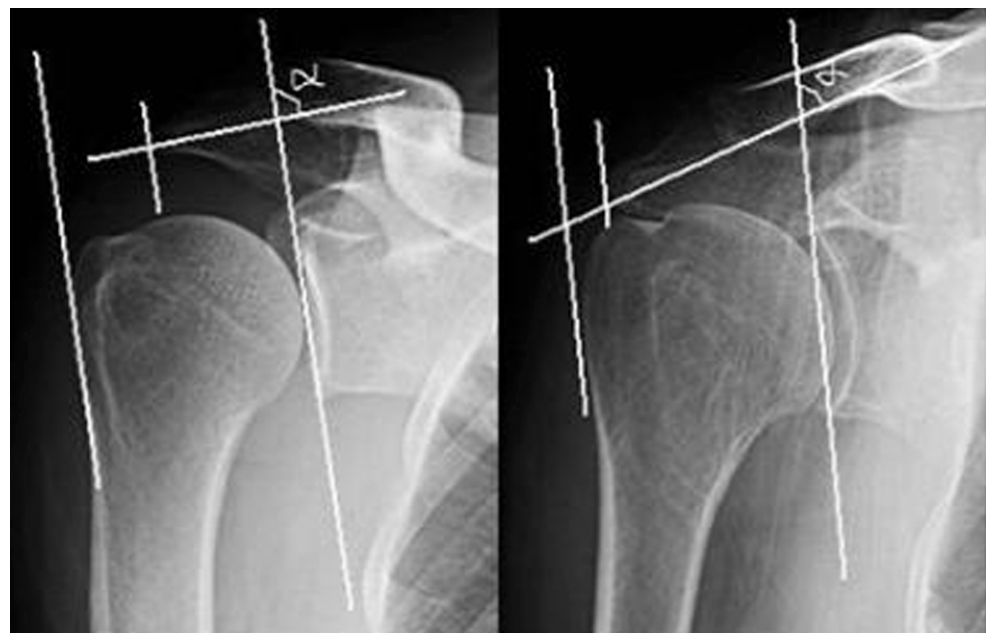

Fig. 5. Radiographs demonstrating an inversely proportional relationship of AI and AA.

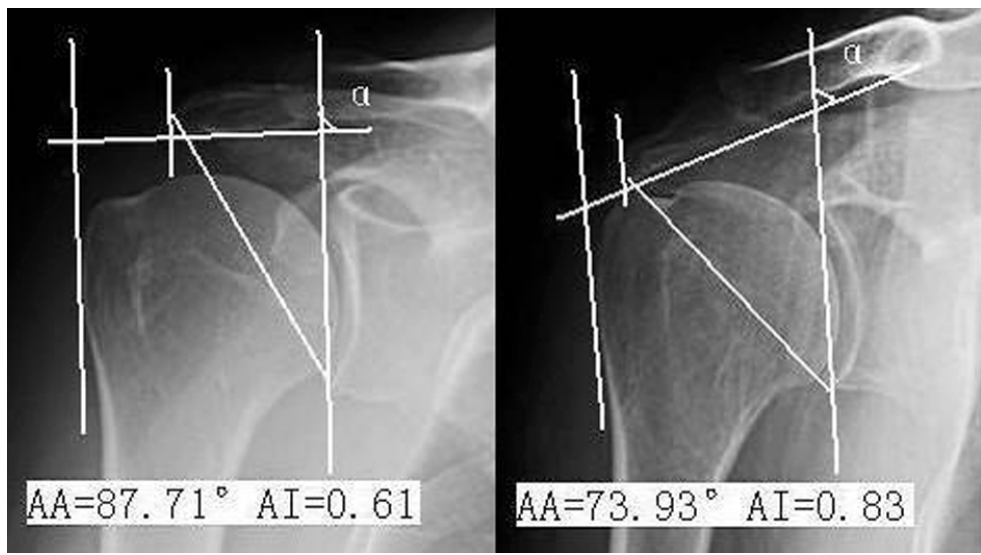

Fig. 6. The different concavities of the acromion to the humeral head.

in the acute group with acute symptoms could have been included in the chronic group. We avoided this limitation by obtaining information thorough clinical histories and examination. However, there could be some overlap between the two groups.

In conclusion, our study demonstrated the correlation between acromial morphology and the incidence of rotator cuff injuries. In addition, the presence of symptoms in acutely injured subjects is likely to impact the clinical assessment of patients, as well as play an important role in the future in predicting the prognosis and determining the optimal management strategy in patients with shoulder pathology.

YU, M-Y.; ZHANG, W.; ZHANG, D-B.; ZHANG, X-D. \& GU, G.S. Estudio antropométrico de la región del hombro en una població china y su relación con la enferemdad del hombro. Int. J. Morphol., 31(2):485-490, 2013.

RESUMEN: Hay escasez de datos que reflejen la relación entre la morfología y la incidencia de los trastornos de hombro con respecto a la población de origen chino. Se utilizó radiografías anteroposteriores para medir el índice acromial (IA) y ángulo acromioglenoido (AA) de los pacientes chinos. La línea de base se define como la que conecta los márgenes óseos superior e inferior de la cavidad glenoidea. Con el fin de calcular el IA, se midió la distancia desde la línea base hasta el margen lateral del acromion y luego se dividió por la distancia desde la línea base hasta la cara lateral de la cabeza humeral. El AA se define como el ángulo formado por la línea de intersección dibujada tangente a la línea esclerótica de la superficie inferior del acromion y el punto de línea base. El AI y AA se determinaron en tres grupos: 165 pacientes (edad media, 60,2 años) con síntomas crónicos en el hombro; en un grupo de 61 pacientes (edad media, 44,3 años) con herida agu$\mathrm{da}$, y en un grupo control de 63 voluntarios (edad media, 37,3 años). La IA promedio fue de 0,72 $\pm 0,06$ en los hombros con el síndrome de pinzamiento subacromial, 0,59 \pm 0,06 en los pacientes con lesión aguda, y 0,66 $\pm 0,06$ en los hombros normales. El AA promedio fue de $76,8^{\circ} \pm 7,02$ en los hombros con el síndrome de pinzamiento subacromial, $84,2^{\circ} \pm 7,81$ en los pacientes con lesión aguda, y 80,0 \pm 7,33 en los hombros normales. La IA y AA variaron entre los pacientes con problemas en el hombro agudos y crónicos.

PALABRAS CLAVE: Ángulo acromioglenoido; Índice acromial; Población china; Lesiones del manguito rotador; Inclinación acromial.

\section{REFERENCES}

Aoki, M.; Ishii, S. \& Usui, M. The slope of the acromion and rotator cuff impingement. Orthop. Trans., 10: 228, 1986.

Banas, M. P.; Miller, R. J. \& Totterman, S. Relationship between the lateral acromion angle and rotator cuff disease. J. Shoulder Elbow Surg., 4 (6):45461, 1995.

Bigliani, L.U.; Morrison, D.S. \& Aprol, E.W. The morphology of the acromion and its relationship to rotator cuff tears. Orthop Trans., 10:216, 1986.

Epstein, R. E.; Schweitzer, M. E.; Frieman, B.G.; Fenlin, J. M. Jr. \& Mitchell, D. G. Hooked acromion: prevalence on MR images of painful shoulders. Radiology. 187(2):479-81, 1993.

Farley, T. E.; Neumann, C. H.; Steinbach, L.S. \& Petersen, S.A. The coracoacromial arch: MR evaluation and correlation with rotator cuff pathology. Skeletal Radiol., 23 (8):641-5, 1994.

Neer, C. S. Anterior acromioplasty for the chronic impingement syndrome in the shoulder: a preliminary report. J. Bone Joint Surg. Am., 54 (1):41-50, 1972. 
Nyffeler, R. W.; Werner, C. M.; Sukthankar, A.; Schmid, M. R. \& Gerber, C. Association of a large lateral extension of the acromion with rotator cuff tears. J. Bone Joint Surg Am., 88 (4):800-5, 2006.

Panni, A. S.; Milano, G.; Lucania, L.; Fabbriciani, C. \& Logroscino, C.A. Histological analysis of the coracoacromial arch: correlation between age-related changes and rotator cuff tears. Arthroscopy, 12(5):531-40, 1996.

Tetreault, P.; Krueger, A.; Zurakowski, D. \& Gerber, C. Glenoid version and rotator cuff tears. J. Orthop. Res., 22 (1):202-7, 2004.

Thompson, M.D.; Landin, D. \& Page, P.A. Dynamic acromiohumeral interval changes in baseball players during scaption exercises. J. Shoulder Elbow Surg., 20(2):251-8, 2011.

Toivonen, D. A.; Tuite, M. J. \& Orwin, J.F. Acromial structure and tears of the rotator cuff. J. Shoulder Elbow Surg., 4 (5):37683, 1995.

Torrens, C.; Lopez, J. M.; Puente, I. \& Caceres, E. The influence of the acromial coverage index in rotator cuff tears. J. Shoulder Elbow Surg., 16(3):347-51, 2007.

Werner, C.M.; Conrad, S.J.; Meyer, D.C.; Keller, A.; Hodler, J. \& Gerber, C. Intermethod agreement and interobserver correlation of radiologic acromiohumeral distance measurements. $J$. Shoulder Elbow Surg., 17 (2):237-40, 2008.

Yamamoto, N.; Muraki, T.; Sperling, J.W.; Steinmann, S.P.; Itoi, E.; Cofield, R. H. \& An, K. N. Contact between the coracoacromial arch and the rotator cuff tendons in nonpathologic situations: a cadaveric study. J. Shoulder Elbow Surg., 19(5):681-7, 2010.
Correspondence to:

Gui-Shan Gu

Department of Orthopaedic Surgery

Jilin University Bethune First Hospital

Changchun 130021

China

Tel: +86-431-88781458

+86-13756661208

Fax: $+86-431-88786101$

Email: guguishan@sina.com

Received: 26-11-2012

Accepted: 25-02-2013 